\title{
ALFABETIZAÇÃO NO CICLO INICIAL DO ENSINO FUNDAMENTAL DE NOVE ANOS: REFLEXÕES SOBRE AS PROPOSIÇÕES DO MINISTÉRIO DA EDUCAÇÃO
}

\author{
Cláudia Maria Mendes Gontijo*
}

\begin{abstract}
RESUMO: Este artigo parte de uma pesquisa documental mais ampla, cuja finalidade foi analisar as políticas de alfabetização infantil implementadas no período de 2003 a 2012. Objetiva compreender as orientações formuladas pelo Ministério da Educação para o ensino fundamental de nove anos relativas à alfabetização infantil. Dessa forma, toma como objeto de análise a orientação intitulada Ensino fundamental de nove anos: orientaçôes gerais (2004) e a coletânea denominada $A$ criança de seis anos, a linguagem escrita e o ensino fundamental de nove anos: orientaçôes para o trabalho com a linguagem escrita com crianças de seis anos de idade (2009). Conclui que as proposiçôes do Ministério da Educação ainda estão pautadas na ideia de carência cultural e, por isso, em grande medida, as orientações para o ensino da linguagem escrita estão fundadas em processos de aquisição de capacidades que visam a suprir tais carências.
\end{abstract}

Palavras-chave: Alfabetização infantil. Leitura. Escrita. Ensino fundamental de nove anos.

\section{LITERACY DURING THE INITIAL CYCLE OF A NINE-YEAR ELEMENTARY SCHOOL: REFLECTIONS ON THE MINISTRY OF EDUCATION'S PROPOSALS}

ABSTRACT: This article is part of a much broader documentary study whose purpose was to analyze the literacy policies for children implemented during the period from 2003 to 2012. The aim of the research is to understand the guidelines provided by the Ministry

Doutora em Educação e professora associada do Centro de Educação da Universidade Federal do Espírito Santo (Ufes).E-mail: clammg@terra.com.br 
Alfabetização no ciclo inicial do ensino fundamental de nove anos...

of Education for a basic education period of nine years as far as childhood literacy is concerned. Thus, the texts which formed the database for the analysis were the policy document entitled Nine-year Elementary School: general guidelines (2004) and the compilation of texts called The six-year-old, written language and nine years of basic education: guidelines for working with written language with six-yearold children (2009). The study concludes that the Ministry of Education's proposals are still guided by the notion of cultural deprivation; therefore, to a large extent, the guidelines for the teaching of written language are rooted in the acquisition process of skills that aim to meet those needs.

Key words: Childhood literacy. Reading. Writing. Nine-year Elementary school.

\section{Considerações iniciais}

A implantação do ensino fundamental de nove anos, instituído pela Lei n. 11.274, de 24 de fevereiro de 2006, concretiza a prioridade prevista no Plano Nacional de Educação (2001) de extensão da escolaridade obrigatória para crianças de 6 anos de idade. Tendo em vista as discussões suscitadas no meio acadêmico e educacional sobre essa mudança e a necessidade de fornecer orientações para a implementação do ensino fundamental do nove anos, o Ministério da Educação (MEC), por meio de seus órgãos e de especialistas contratados para esse fim, elaborou documentos que visaram a fornecer orientações para a inclusão das crianças de 6 anos de idade no ensino fundamental. A primeira orientação foi produzida antes mesmo da regularização por lei do ensino fundamental de nove anos. As outras duas foram elaboradas após a promulgação da Lei n. 11.274, de 24 de fevereiro de 2006, e se detiveram mais especificamente sobre o ensino da leitura e da escrita.

Assim, com base nessas orientaçóes, elaboramos este artigo, que tem por finalidade compreender orientações formuladas pelo MEC para o ensino fundamental de nove anos no que diz respeito à alfabetização. Dessa forma, tomamos como objeto de análise a orientação intitulada Ensino fundamental de nove anos: orientaçôes gerais (2004) e textos da coletânea A criança de seis anos, a linguagem escrita e o ensino fundamental de nove anos: orientaçôes para o trabalho com a linguagem escrita com crianças de seis anos de idade (2009). 


\section{Orientações gerais para o ensino fundamental de nove anos}

Como mencionamos, antes da normatização em lei do ensino fundamental de nove anos, o MEC publicou, juntamente com a Secretaria de Educação Básica, com o Departamento de Políticas de Educação Infantil e Ensino Fundamental (DPE) e com a Coordenação Geral do Ensino Fundamental (Coef), o documento denominado Ensino fundamental de nove anos: orientaçôes gerais (2004). Esse documento afirma o compromisso do Ministério com a melhoria da educação nacional por meio da ampliação do ensino fundamental para nove anos. Além de elencar dispositivos legais que fundamentam a ampliação e dados históricos sobre a educação nacional e que apontam para uma progressiva expansão do ensino obrigatório, o MEC apresenta razôes que explicam o ensino fundamental a partir dos 6 anos.

Assim, em primeiro lugar, com base no Censo Demográfico de 2000, realizado pelo Instituto Brasileiro de Geografia e Estatística (IBGE), o Ministério menciona dados relativos à matrícula das crianças de 6 anos em instituições escolares: "[...] 81,7\% das crianças de 6 anos estão na escola, sendo que 38,9\% frequentam a Educação Infantil, 13,6\% as classes de alfabetização e 29,6\% já estão no Ensino Fundamental" (MEC, 2004, p. 17). Nesse sentido, o tipo de ampliação pretendida aumentaria esses números e atenderia, principalmente, às crianças das classes populares, tendo em vista que as de classes média e alta já estão, na perspectiva do MEC, incluídas em sistemas educativos privados.

Em segundo lugar, a antecipação do acesso estaria contextualizada nas políticas que incidem sobre o ensino fundamental. Porém, conforme adverte o texto do documento, não se trata, com essa medida, de transferir para as classes de seis anos os mesmos conteúdos da primeira série, "[...] mas de conceber uma nova estrutura de organização dos conteúdos em um Ensino Fundamental de nove anos, considerando o perfil de seus alunos" (idem, ibid.). Sendo assim, a ampliação dessa etapa da escolarização trouxe em seu cerne elementos que poderiam ter reflexos positivos sobre o ensino fundamental, que também atende a crianças, mas está assentado sobre modelos de organização curricular e de organização do tempo inadequados ao público infantil que frequenta os anos iniciais de escolarização. Entretanto, como veremos posteriormente, as orientaçôes para o ensino da linguagem escrita nas classes de crianças de 6 anos não ajudam a repensar o ensino fundamental na perspectiva de sua reorganização. Pelo contrário, 
Alfabetização no ciclo inicial do ensino fundamental de nove anos...

como medida compensatória, contribui para antecipar práticas de ensino realizadas na antiga primeira série.

O documento aponta ainda que a ampliação da escolaridade obrigatória, associada à melhor utilização do tempo escolar, pode trazer benefícios para a aprendizagem. Com relação a esse aspecto, é importante salientar que o tempo que se amplia é o destinado à alfabetização. Sabemos que, nas décadas de 1980 e 1990 (para lembrar as décadas mais recentes em que a adoção desse tipo de sistema ocorreu), a implantação dos sistemas de ciclos também visou à expansão desse tempo. Nesses contextos, no entanto, tal medida se mostrou insuficiente para garantir aumentos significativos dos índices de rendimento escolar e de aprovação ao final do ciclo. Sendo assim, a preocupação com a ampliação do tempo pode não contribuir para o sucesso da atual medida, principalmente quando se mantém uma organização curricular que afirma modelos de alfabetização e de educação das crianças fundados na ideia de carência cultural. Para o sucesso da medida que visa à melhoria da qualidade da educação oferecida às crianças, talvez fosse necessário pensar em políticas conjugadas de valorização do magistério, de melhoria das condições de trabalho dos professores e, sobretudo, políticas de distribuição de riquezas que conduzam à melhoria das condições de vida da população pobre e dos professores que atuam na educação básica.

As orientações apresentam ainda uma caracterização, em termos psicológicos e afetivos, das crianças de 6 anos que ingressam no ensino fundamental. Tal caracterização afirma que os aspectos psicológicos se sobrepóem a uma caracterização por idade, mas, contraditoriamente, apoiada em práticas e pesquisas não explicitadas, assinala que as crianças de 6 anos se distinguem das de outras idades. Dessa maneira, indica que a atividade central das crianças de 6 anos é a brincadeira, e é por meio dessa atividade central que elas conhecem o mundo. Em termos cognitivos, as crianças já são capazes de trabalhar com símbolos e, por isso mesmo, estão aptas a fazer uso de diferentes linguagens e de participar de jogos envolvendo o uso de regras. Essa caracterização, portanto, abrange aspectos psicológicos e afetivos do desenvolvimento infantil que servem de parâmetros para afirmar a capacidade da criança de 6 anos de aprender a linguagem escrita e, portanto, para ser alfabetizada nessa faixa etária.

Ao mesmo tempo, reconhece que muitas crianças têm contato com a escrita apenas no momento em que ingressam no processo formal de escolarização: "Desse modo, o direito da criança a um maior tempo de 
escolaridade obrigatória deve ser compreendido como ampliação de suas oportunidades de aprender e de interagir com parceiros da mesma idade e com outros mais experientes" (MEC, 2004, p. 22). O documento salienta também que as crianças que vivem em meios sociais letrados possuem um forte desejo de aprender e que as possibilidades de aprendizagem são determinadas "[...] pelas experiências e pela qualidade das interações às quais se encontram expostas no meio sociocultural em que vivem ou que frequentam" (ibid., p. 20), tendo a família, a escola e os professores um papel central como mediadores culturais. Em relação ao aprendizado da linguagem escrita, conforme assinalado nas orientações, a escola tem papel decisivo, principalmente quando se trata de crianças oriundas de famílias de baixa renda e escolaridade.

Sendo assim, podemos inferir que o texto produzido pelo MEC (2004) conduz à ideia de que, em termos psicológicos e afetivos, as crianças de 6 anos, em geral, têm condições de aprender. Porém, àquelas que vivem em meios sociais onde a aprendizagem da linguagem escrita não é estimulada, é necessário que a escola garanta mais tempo de aprendizado para suprir possíveis carências que afetam diretamente o desenvolvimento infantil e, portanto, o sucesso escolar. Como veremos, as orientações posteriores do MEC e de seus especialistas caminham em direção à constituição do que podemos chamar de "currículo inicial" baseado no "treino" da consciência fonológica, considerada essencial na aquisição da leitura e da escrita. Sendo assim, por meio de atividades metafonológicas, seriam supridas as carências das crianças que vivem em meios sociais pobres de estímulos, nos quais também os mediadores culturais são analfabetos ou semialfabetizados.

Não podemos deixar de lamentar que, na atualidade, os fundamentos para implementação de políticas educacionais, no campo da alfabetização infantil, estejam ainda pautados na correlação entre níveis satisfatórios de aprendizagem e classe social, porque a visão que sustenta a ideia de que as crianças pobres possuem carências que precisam ser supridas pela escola no momento inicial da alfabetização parte de uma

[...] concepção biologizada da vida social e com uma definição etnocêntrica de cultura: de um lado, o ambiente é praticamente reduzido à estimulação sensorial proveniente do meio físico; de outro, valores, crenças, normas, hábitos e habilidades tidos como típicos das classes dominantes são considerados como os mais adequados à promoção de um desenvolvimento psicológico sadio. (PATTO, 1999, p. 68) 
Alfabetização no ciclo inicial do ensino fundamental de nove anos...

Como mostramos, o documento do MEC aponta as características psicológicas ideais das crianças de 6 anos de idade e afirma que as experiências anteriores são determinantes da aprendizagem. Como as crianças pobres vivem em meios sociais e culturais "pobres de estímulos", a ampliação do ensino fundamental poderá contribuir para o sucesso escolar dessas crianças. Patto (op. cit.), ao analisar estudos norte-americanos que têm fundamentado essa visão, assinala que essas pesquisas confirmam, para os educadores, uma visão preconceituosa sobre crianças pobres e suas famílias. Desse modo, impedem que os educadores percebam as razóes que levam as crianças pobres a fracassar na escola.

Dizem para os oprimidos que a deficiência é dele e lhe prometem uma igualdade de oportunidades impossível através dos programas de educação compensatória que já nascem condenados ao fracasso, quando partem do pressuposto de que seus destinatários são menos aptos à aprendizagem escolar. (PATTO, op. cit., p. 70)

Nesse sentido, devemos acrescentar que a ampliação do ensino fundamental para nove anos não pode ser vista como uma das muitas formas de educação compensatória, que têm por finalidade específica apenas antecipar o treino de habilidades cognitivas e motoras pensadas como essenciais para o processo de alfabetização. Quando analisamos textos da coletânea que apresenta orientações específicas para o ensino da linguagem escrita nas classes de crianças com 6 anos de idade, parece que esse é o objetivo central.

\section{Orientações para o ensino da linguagem escrita}

Apesar de termos conhecimento da primeira coletânea de textos que visou a fornecer orientações para a inclusão das crianças de 6 anos no ensino fundamental, considerando os limites deste artigo, nos detivemos a examinar a coletânea publicada em 2009, porque ela se dedica exclusivamente a apresentar orientações para o ensino da linguagem escrita nas classes de crianças com 6 anos. $\mathrm{O}$ tratamento exclusivo dessa dimensão da formação infantil na escola de ensino fundamental é explicado "[...] por seu caráter complexo, multifacetado e precursor, [que] cumpre um papel fundamental na garantia do direito à educação: o desenvolvimento da linguagem escrita" (MONTEIRO; BAPTISTA, 2009, p. 7). 
A partir da explicação de que a segunda parte da coletânea discute as dimensões da alfabetização nas classes de 6 anos, pretendemos, então, buscar compreender as orientaçóes para o trabalho com cada uma dessas dimensões: a) o letramento, b) o desenvolvimento das habilidades de leitura e escrita de palavras, frases e textos em sala de aula, c) a aquisição do sistema de escrita e o desenvolvimento da consciência fonológica e d) o desenho e a brincadeira: formas de linguagem a serem exploradas no processo de alfabetização. Assim, a primeira dimensão da proposta pedagógica para o ensino da linguagem escrita é o letramento. Inicialmente, no texto que trata dessa dimensão, Monteiro e Baptista (2009) lembram a necessidade de que as quatro dimensōes da alfabetização sejam tratadas integradamente. Antes, porém, de iniciarem a discussão da dimensão do letramento, discutem como concebem o ato de ler e escrever. Nessa direção, apontam que, por meio da leitura, o leitor interage com o texto para retirar dele informaçōes implícitas e explícitas. Escrever, por sua vez, é uma atividade complexa que envolve a escolha correta de elementos linguísticos que permitem o controle dos sentidos. Se, ao definir o primeiro termo, as autoras pretendem se afastar do conceito de leitura como decodificação, com relação ao escrever, pretendem se afastar de certa concepção de escrita como transcrição do pensamento. No entanto, essas concepções não têm impactos importantes nas discussōes desenvolvidas nos textos, porque as autoras acabam por absorver nas suas propostas o conceito de leitura ao qual se opõem em princípio - como processo de decodificação - e, consequentemente, de escrita como processo de codificação. Elas buscam, também, quando se trata da escrita, absorver elementos das teorizaçôes de Ferreiro e Teberosky e dos defensores da consciência fonológica, considerada, de acordo com os estudos das autoras sobre a psicogênese da língua escrita, como resultado da aprendizagem da leitura e da escrita.

Grosso modo, podemos dizer que os conceitos de alfabetização e de letramento apresentados pelas autoras estão fundamentados em Soares (2004). Apontam, dessa forma, que o letramento ou condição letrada é resultado, entre outros fatores, da convivência com pessoas letradas, da participação em eventos de letramento e do desenvolvimento das capacidades de leitura e de escrita (alfabetização). Os três elementos citados por Monteiro e Baptista justificam, de certo modo, a ampliação do ensino fundamental e a consequente inclusão das crianças de 6 anos na segunda etapa da educação básica, principalmente se considerarmos, conforme escrito nas primeiras

Cad. Cedes, Campinas, v. 33, n. 89, p. 35-49, jan.-abr. 2013 
Alfabetização no ciclo inicial do ensino fundamental de nove anos...

orientações (2004), as dificuldades de grande parte das crianças brasileiras em conviver com pessoas letradas e em participar de eventos de letramento.

Para se contraporem aos métodos de alfabetização que não privilegiam o letramento, as autoras concluem que é um equívoco pensar que “[...] aprender a ler e a escrever é apropriar-se de um código e não de um sistema de representação" (MONTEIRO; BAPTISTA, 2009, p. 30; grifos nossos). Dessa forma, para as autoras, a diferença entre os termos destacados na citação não é apenas terminológica, pois a adoção de uma ou de outra concepção de escrita tem consequências pedagógicas diferenciadas. Consonantes com as conclusões de Ferreiro (1990), Monteiro e Baptista (op. cit., p. 39) esclarecem que:

[...] conceber a escrita como um código de transcrição implica conceber que sua aprendizagem consiste na aquisição de uma técnica. Conceber a escrita como um sistema de representação converte sua aprendizagem na apropriação de um novo objeto de conhecimento, ou seja, em uma aprendizagem conceitual.

Trocando em miúdos, conforme sublinham Monteiro e Baptista (op. cit., p. 30; grifos nossos), a alfabetização "[...] se refere ao processo por meio do qual o sujeito domina o código e as habilidades de utilizá-lo para ler e escrever. Trata-se do domínio da tecnologia, do conjunto de técnicas que o capacita a exercer a arte e a ciência da escrita". Sendo assim, é importante ponderar que, segundo Abbagnamo (1990, p. 942), o termo tecnologia pode ser definido como: 1. "[...] estudo dos processos técnicos de determinado ramo da produção industrial ou de vários ramos", 2. "o mesmo que técnica", 3. "o mesmo que tecnocracia". Considerando os três sentidos e a definição das autoras, podemos dizer que a alfabetização é o estudo pelos aprendizes dos processos técnicos envolvidos na produção de escrita e da leitura ou o processo de aprendizagem da técnica da escrita. Desse modo, refere-se à aprendizagem de um conjunto de procedimentos manuais (motores) e cognitivos (envolvendo capacidade de associação entre estímulos sonoros e gráfico-visuais). Assim, no cerne das orientações oficiais, a alfabetização é reduzida ao processo de aquisição do código escrito, ou seja, à aprendizagem da técnica da escrita. O letramento, por sua vez, diz respeito à capacidade de fazer uso desses procedimentos em práticas sociais.

$\mathrm{O}$ segundo texto - $O$ desenvolvimento das habilidades de leitura e escrita de palavras, frases e textos na sala de aula - ajuda a aprofundar 
questões conceituais e práticas. As autoras assinalam que a compreensão da natureza alfabética do sistema de escrita capacita as crianças a ler e a escrever palavras. Dessa forma, para elas, o desenvolvimento da leitura e da escrita de palavras exige tempo e "treino". Por isso mesmo, o professor deve elaborar um conjunto de atividades envolvendo a escrita e a leitura de palavras e frases.

Assim, as autoras mencionam a necessidade de levar as crianças a ler e a interpretar textos e, também, são apresentadas sugestões que visam a auxiliar o professor no processo de letramento inicial, pois este está ligado ao trabalho com textos na escola. Há atividades específicas para alfabetizar e para letrar. As primeiras estão relacionadas com a leitura e a escrita de palavras e frases. As atividades referentes ao letramento estão associadas, em grande medida, a ler e escrever de forma compartilhada.

As atividades ligadas à alfabetização são mais bem detalhadas no terceiro texto da coletânea, intitulado "A aquisição do sistema de escrita e o desenvolvimento da consciência fonológica”. Nesse texto, as autoras aprofundam aspectos ligados à compreensão da escrita como sistema de representação. Nesse sentido, em acordo com os postulados de Ferreiro (1990), assinalam que as crianças terão que lidar com dois planos da linguagem (do significado e do significante). Afirmam ainda que a compreensão do princípio alfabético da escrita e a consciência fonológica integram o processo de compreensão do sistema de representação (escrita): "O termo consciência fonológica refere-se a um conjunto de habilidades relacionadas à capacidade de a criança refletir e analisar a língua oral. Capacidades que serão desenvolvidas ao longo do processo de aquisição do sistema de escrita" (MONTEIRO; BAPTISTA, 2009, p. 59).

Monteiro e Baptista (op. cit.) assumem que a compreensão do princípio alfabético da escrita passa por fases já identificadas por estudos psicogenéticos, reconhecendo, portanto, que são independentes das aprendizagens e que existe um percurso de desenvolvimento da linguagem escrita que está delineado antes mesmo de as crianças nascerem. A consciência fonológica se desenvolve nesse percurso, pois, ao escrever palavras, as crianças primeiramente tomam consciência da unidade sílaba e, depois, dos fonemas. Desse modo, a consciência fonêmica não é um requisito para a aprendizagem da escrita. Ela é o resultado do processo de desenvolvimento da escrita da criança. Por isso mesmo, é necessário construir uma proposta que leve em conta o trabalho com as unidades menores da língua (palavras, sílabas e 
Alfabetização no ciclo inicial do ensino fundamental de nove anos...

letras). Com relação ao processo de aquisição da consciência fonológica, as autoras assim se posicionam:

Os estudos sobre a relação entre consciência fonológica e alfabetização vêm demonstrando o importante papel das habilidades metafonológicas no processo de aquisição da leitura e da escrita num sistema alfabético. No entanto, pode-se dizer que essas habilidades se desenvolvem concomitantemente a esse processo; e não previamente. (Idem, ibid., p. 59)

Curiosamente, os "estudos" que demonstram o importante papel das habilidades metafonológicas, ou seja, as habilidades de refletir ou isolar unidades da língua oral, cuja referência consta no final da segunda parte da coletânea, são representados por apenas um artigo, de autoria de Sylvia Domingos Barrera e Maria Regina Maluf, intitulado "Consciência metalinguística e alfabetização: um estudo com crianças da primeira série do ensino fundamental", publicado na revista Psicologia: reflexão e crítica, em 2003. O objetivo desse trabalho é analisar a influência da consciência lexical e sintática na aprendizagem da linguagem escrita. Os resultados desse estudo indicam que:

[...] as crianças que apresentaram melhor desempenho em leitura e escrita no final do ano foram aquelas que iniciaram o processo de alfabetização com níveis superiores no desenvolvimento da consciência metalinguística, sobretudo em seus aspectos fonológico e sintático. Quanto à consciência lexical, esta apresentou correlação menor, mas ainda assim estatisticamente significativa, com o desempenho final em leitura. (BARRERA; MALUF, 2003, p. 496)

Dessa maneira, os resultados evidenciam que a consciência fonológica (fonêmica e silábica) e a consciência sintática estão diretamente associadas ao bom desempenho em leitura e escrita. De acordo com os estudos de Ferreiro e Teberosky (1989), as consciências silábica e fonêmica integram a evolução da escrita, donde Monteiro e Baptista parecem concluir sobre a necessidade de propor situações de aprendizagem específicas para cada nível de evolução da escrita que levem as crianças a adquirir, primeiro, consciência da unidade sílaba e, depois, do fonema. Desse modo, elaboram atividades para serem desenvolvidas na fase silábica e silábico-alfabética. As situações de aprendizagem, para a fase silábica, restringem-se ao trabalho com sílabas, mesmo sabendo que as crianças já têm consciência dessa unidade. A palavra é usada apenas como contexto linguístico para 
identificação dessas unidades. Para a fase silábico-alfabética e alfabética, é incluído, além do trabalho com sílabas, o trabalho com fonemas, palavras, frases, uso do caderno e cópia.

Se observarmos muitas das cartilhas de marcha sintética usadas durante todo o século XX, verificaremos que há muitas semelhanças entre a sequência de atividades proposta nesses suportes com as situaçõos de aprendizagem apresentadas por Monteiro e Baptista (2009) - separação de sílabas, identificação de sílabas em palavras, cópia, identificação de fonemas, entre outras. Porém, as situações propostas por essas autoras se revestem de novas bases científicas - o construtivismo e as pesquisas sobre consciência fonológica -, atribuindo a elas um caráter inovador.

É importante enfatizar, com relação à proposta apresentada pelas autoras, que a criança idealmente concebida deve passar por determinadas fases de desenvolvimento que levam à aquisiçãa do código alfabético. Durante as fases, ela deve ser "treinada" de modo a adquirir consciência fonêmica, pois, nesse momento, ela estaria, em sentido restrito, alfabetizada. Não pretendemos retomar, aqui, os debates acerca dessa questão, mas é importante apontar que o modo como são organizadas as atividades a serem desenvolvidas pelas crianças em cada fase remete a propostas cuja unidade de ensino é, em primeiro lugar, a palavra, porque esta pode ser desintegrada em unidades menores. Por outro lado, o trabalho com as sílabas ocupa lugar central no processo de alfabetização.

Devemos lembrar, no entanto, que os estudos sobre alfabetização têm demonstrado que as práticas alfabetizadoras, antes mesmo das orientações elaboradas por Monteiro e Baptista (op. cit.), estavam/estão centradas no trabalho com essas unidades da língua, o que não tem contribuído para a melhoria dos índices de bom desempenho em leitura e escrita. Confirmam essa afirmação os trabalhos realizados sobre as apropriaçōes ou usos que os professores fazem dos livros didáticos indicados no Programa Nacional do Livro Didático, sustentados pelo construtivismo e pela perspectiva do letramento. Segundo Silva (2005, p. 190), os professores escolhem os livros didáticos observando, entre outros critérios, a presença de textos curtos, pois esses "[...] são utilizados como instrumentos para contextualização do sistema alfabético, tais como: identificação e estudo de determinadas palavras, frases, de composição de palavras em sílabas ou simplesmente identificação de letras". Assim, os professores escolhem livros e, também, selecionam tarefas em diversos livros didáticos que se assemelham àquelas indicadas em

Cad. Cedes, Campinas, v. 33, n. 89, p. 35-49, jan.-abr. 2013

Disponível em <http://www.cedes.unicamp.br> 
Alfabetização no ciclo inicial do ensino fundamental de nove anos...

cartilhas organizadas de acordo com os antigos métodos de alfabetização, o que demonstra que as práticas de ensino de palavras e sílabas não foram abandonadas pelos alfabetizadores e continuam, de certa maneira, a serem incentivadas nas propostas oficiais.

Infelizmente, essas orientações, para o ensino da linguagem escrita nas classes de 6 anos, levam-nos a pensar, tendo em vista as justificativas para a ampliação do ensino fundamental para nove anos, que, mesmo revestidas de bases científicas novas, pretendem garantir que a criança, aos 6 anos, adquira consciência fonêmica, pois essa aquisição é fundamental para a aprendizagem da leitura e da escrita. Desse modo, o que se propóe é a antecipação do que era feito na primeira série com crianças de 7 anos para o primeiro ano que, agora, tem crianças de 6 anos, como medida compensatória para suprir as supostas carências infantis.

Para finalizar as análises das propostas elaboradas por Monteiro e Baptista (2009), é importante destacar que, ao desenho e à brincadeira, última dimensão da alfabetização discutida pelas autoras, poucas páginas são dedicadas, demonstrando que essas atividades são consideradas menos relevantes. Não iremos aprofundar esse aspecto, mas é importante salientar que Bakhtin (1999, p. 204), ao analisar, nos romances de Rabelais, as formas e as imagens da festa popular na Idade Média e no Renascimento, sublinha a importância dos jogos, da brincadeira. Segundo esse autor, "[...] o jogo fazia o homem sair dos trilhos da vida comum, liberava-o das suas leis e regras, substituía às convenções correntes outras convenções mais densas, alegres e ligeiras". Nesse sentido, Bakhtin assinala que o jogo e a brincadeira proporcionam a constituição de outra concepção de mundo, distinta da visão oficial, que liberta, pois, no jogo, na brincadeira, podemos imaginar uma realidade livre das opressões, sem medo de fazê-lo. Assim, essa dimensão da alfabetização é fundamental para o desenvolvimento integral das crianças. Entretanto, conforme apontado, o ensino da técnica da escrita tem lugar privilegiado nas situaçôes de aprendizagem analisadas.

\section{Considerações finais}

Neste momento, é importante levar em conta pelo menos um questionamento decorrente das análises dos documentos orientadores da inclusão das crianças de 6 anos no ensino fundamental: por que o trabalho com a sílaba teima em permanecer fortemente na proposta pedagógica 
examinada? Ensaiaremos possíveis respostas, sem a pretensão de esgotá-las. Talvez, porque, considerando as orientaçōes iniciais para a implementação do ensino fundamental de nove anos, é necessário que a proposta ajude a suprir determinadas carências das crianças das classes populares. Supostamente, elas chegam à escola sem ter consciência das unidades fonológicas essenciais que proporcionam a aquisição do sistema alfabético de escrita, conforme têm demonstrado os estudos nesse campo. Nesse sentido, as situações de aprendizagem ajudam a suprir essas carências com a antecipação de atividades antes propostas na primeira série, o que, em nossa opinião, pode dificultar a pensar a reorganização do tempo, do espaço e dos currículos escolares, de modo a levar em conta as necessidades das crianças de 6, 7, 8, 9 anos que frequentam o ensino fundamental.

Além disso, segundo os estudos voltados para a consciência fonológica, a consciência fonêmica e a consciência silábica estão diretamente relacionadas com o sucesso na alfabetização. Os estudos de Ferreiro (1990) assinalam que a consciência fonêmica ou a aquisição do caráter alfabético da escrita resultam do processo de evolução da escrita nas crianças. Essas duas posiçôes, aparentemente contraditórias, parecem levar as autoras dos textos que compõem a coletânea a concluir sobre a necessidade de a alfabetização (processo de aquisição da técnica da escrita) enfatizar, em princípio, o ensino-aprendizagem de palavras e sílabas. Essa conclusão nos permite inferir que as autoras supõem que todas as crianças que entram nas classes de primeiro ano já construíram a hipótese silábica e, por isso, as situações de aprendizagem que envolvem o trabalho com sílabas e palavras podem levá-las a construir as hipóteses silábico-alfabética e alfabética. Sendo assim, podemos pensar que as situações de aprendizagem destacadas, para a hipótese silábica, ainda, ajudariam as crianças a elaborar essa hipótese silábica. Desse modo, a proposição desse tipo de atividade atenderia a crianças em diferentes níveis de aprendizado.

Apesar de buscarmos entender as razões que levam, principalmente no segundo documento analisado, a enfatizar o ensino da palavra e da sílaba, outra pergunta ainda permanece: a quem e a quê esse tipo de ensino serve? Podemos, novamente, ensaiar muitas outras possíveis respostas, mas deixaremos a cargo de cada leitor a busca de respostas para essa questão, pois já ultrapassamos os limites deste texto. 
Alfabetização no ciclo inicial do ensino fundamental de nove anos...

Referências

ABBAGnAmO, N. Dicionário de filosofia. São Paulo: Martins Fontes, 1990.

BAKHTIN, M. A cultura popular na Idade Média e no Renascimento: o contexto François Rabelais. São Paulo: Hucitec; Brasília, DF: UnB, 1999.

BARRERA, S.D.; MALUF, M.R. Consciência metalinguística e alfabetização: um estudo com crianças da primeira série do ensino fundamental. Psicologia: reflexão e crítica, São Paulo, v. 3, n. 16, p. 491-502, 2003.

BRASIL. Lei n. 9.394, de 20 de dezembro de 1996. Estabelece as diretrizes e bases da educação nacional. Diário Oficial da Uniāo, Brasília, DF, 23 dez 1996. Disponível em: <www.planalto.gov.br/>. Acesso em: 29 maio 2011.

BRASIL. Lei 11.274, de 6 de fevereiro de 2006. Altera a redação dos arts. 29, 30, 32 e 87 da Lei n. 9.394, de 20 de dezembro de 1996, dispondo sobre a duração de 9 anos para o ensino fundamental, com matrícula obrigatória a partir dos 6 anos de idade. Diário Oficial da Uniāo, Brasília, DF, 7 fev. 2006.

BRASIL. Ministério da Educação. Secretaria de Educação Básica. Ensino fundamental de nove anos: orientaçôes gerais. Brasília, DF: MEC/SEB, 2004. Disponível em: <portal.mec.gov.br/seb/arquivos/pdf/Ensfund/ noveanorienger.pdf >. Acesso em: 29 maio 2011.

BRASIL. Plano Nacional de Educação. Brasilia, DF: Senado Federal; Unesco, 2001.Disponível em: < portal.mec.gov.br/arquivos/pdf/pne.pdf>. Acesso em: 16 jul. 2012.

FERREIRO, E. Reflexōes sobre alfabetização. 16. ed. São Paulo: Cortez; Campinas: Autores Associados, 1990.

FERREIRO, E.; TEBEROSKY, A. Psicogênese da lingua escrita. Porto Alegre: Artes Médicas, 1989.

MONTEIRO, S.M. (Org.). A criança de 6 anos, a linguagem escrita e o ensino fundamental de nove anos: orientaçōes para o trabalho com a linguagem escrita em turmas de crianças de 6 anos de idade. Belo Horizonte: UFMG; FAE; Ceale, 2009. 
MONTEIRO, S.M.; BAPTISTA, M.C. Dimensões da proposta pedagógica para o ensino da linguagem escrita em classes de crianças de 6 anos. In: MACIEL, F.I.P.; BAPTISTA, M.C.; MONTEIRO, S.M. (Org.). A criança de 6 anos, a linguagem escrita e o ensino fundamental de nove anos: orientações para o trabalho com a linguagem escrita em turmas de crianças de 6 anos de idade. Belo Horizonte: UFMG; FAE; Ceale, 2009.

PATTO, M.H.S. A produção do fracasso escolar: histórias de submissão e rebeldia. São Paulo: Casa do Psicólogo, 1999.

SILVA, C.R. Formas de uso dos novos livros didáticos de alfabetização: por que os professores preferem os métodos tradicionais? In: VAL, M.G.C.; MARCUSCHI, B. (Org.). Livros didáticos de língua portuguesa: letramento e cidadania. Belo Horizonte: Ceale; Autêntica, 2005. p. 185-204.

SOARES, M.B. Letramento e alfabetização: as muitas facetas. Revista Brasileira de Educação, São Paulo, n. 25, p. 5-17, 2004.

Recebido em 30 de setembro de 2012.

Aprovado em $1^{\circ}$ de março de 2013. 